IEEE ISIE International Symposium on Industrial Electronics, Rio de Janeiro Brazil, pp.184-189, June 2015.

http://ieeexplore.ieee.org/stamp/stamp.jsp?tp=\&arnumber $=7281466$

ISBN: 978-1-4673-7553-5

DOI 10.1109/ISIE.2015.7281466

This material is posted here with permission of the IEEE. Such permission of the IEEE does not in any way imply IEEE endorsement of any of Group of Energy and Power Electronics, University of Minho, products or services. Internal or personal use of this material is permitted. However, permission to reprint/republish this material for advertising or promotional purposes or for creating new collective works for resale or redistribution must be obtained from the IEEE by writing to pubs-permissions@ieee.org. By choosing to view this document, you agree to all provisions of the copyright laws protecting it.

(C) 2015 IEEE 


\title{
A Novel Architecture of a Bidirectional Bridgeless Interleaved Converter for EV Battery Chargers
}

\author{
Vítor Monteiro $^{1}$, Bruno Exposto ${ }^{1}$, J. G. Pinto ${ }^{1}$, J. C. Aparício Fernandes ${ }^{1}$, Luís F. C. Monteiro ${ }^{2}$, João L. Afonso ${ }^{1}$ \\ ${ }^{1}$ ALGORITMI Research Centre - University of Minho, Guimarães - Portugal \\ ${ }^{2}$ Universidade do Estado do Rio de Janeiro, Campus Francisco Negrão de Lima - 20559-900, Rio de Janeiro, Brasil \\ ${ }^{1}$ \{vitor.monteiro | bruno.exposto | gabriel.pinto | aparicio.fernandes | joao.1.afonso\}@algoritmi.uminho.pt ${ }^{2}$ Imonteiro@uerj.br
}

\begin{abstract}
This paper presents a novel architecture of a bidirectional bridgeless interleaved converter for battery chargers of electric vehicles (EVs). The proposed converter is composed by two power stages: an ac-dc converter that is used to interface the power grid and the dc-link, and a dc-dc converter that is used to interface the dc-link and the batteries. The ac-dc converter is an interleaved bridgeless bidirectional boost-type converter and the dc-dc converter is a bidirectional buck-boost-type converter. The proposed converter works with sinusoidal grid current and with high power factor for all operating power levels, and in both grid-to-vehicle (G2V) and vehicle-to-grid (V2G) operation modes. In the paper is described in detail the proposed converter for $\mathrm{EV}$ battery chargers: the circuit topology, the principle of operation, the power control theory, and the current control strategy. Several simulation results for both G2V and V2G operation modes are presented.
\end{abstract}

Keywords-Bidirectional; Interleaved; Bridgeless; Battery Charger; Electric Vehicle.

\section{INTRODUCTION}

The electric mobility represents an important contribution to minimize the greenhouses gases emissions caused by the actual scenario in the transport sector. In this situation, the electric vehicle $(\mathrm{EV})$ is the main solution to a more sustainable and efficient mobility [1][2]. Besides the electric mobility, where are included the grid-to-vehicle (G2V) and vehicle-to-grid (V2G) operation modes, the EV battery chargers can also be used for other purposes, for instance: the operation as vehicle-to-home [3]; or the operation as reactive power compensator [4][5]. In any of the aforementioned operation modes, the EV introduction in the power grids cannot neglect the power quality and the power grid stability [6][7]. In order to perform the EV battery charging process from the power grid is required a battery charger, which can be installed inside (on-board) or outside (off-board) the EV. Typically, both EV battery chargers are composed by two power stages, i.e., comprising an ac-dc converter (front-end) and a dc-dc converter (back-end). For the ac-dc converter it is important ensure grid currents with low harmonic distortion and high power factor [8][9]. For the dc-dc converter it is important ensure controllable output voltage and current. In [10] is presented a set of modular three-phase converters based in current-source converters for applications of EV battery chargers. On the other hand, in [11] is presented a set of three-phase converters based in voltage-source converters also for applications of EV battery chargers. Taking into account that the EV battery chargers based in the voltage-source converter are boost-type, the output voltage is always greater than the maximum instantaneous value of the power grid voltage. On the other hand, using a current-source converter (buck-type), the output voltage is always lower than the maximum instantaneous value of the power grid voltage. In [12] is presented a review about the actual status of EV battery chargers, where are included the topologies of converters, the charging power levels and the infrastructures for EVs. In this context, in [13] and [14] is presented an exhaustive review about the essence of three-phase converters, including bidirectional and unidirectional topologies, as well as active and passive topologies. Similar studies can be found in the literature for single-phase converters [15][16]. For the ac-dc front-end converter, besides the full-bridge and half-bridge bidirectional active converters, the main topologies are based in the bridgeless converters [17][18], and multilevel converters [19][20]. On the other hand, for the dc-dc back-end non-isolated converter, the main topologies are based in the half-bridge converter [21], the interleaved converters [22], and cascade converters [23]. In this context, this paper presents a novel bidirectional converter for EV battery chargers. This converter is presented in Fig. 1. As it can be seen, this converter is composed by two converters: an ac-dc that is used to interface the power grid and the dc-link; and a dc-dc that is used to interface the dc-link and the batteries. The ac-dc converter is an interleaved bridgeless bidirectional boost-type converter with voltage-doubler characteristic, i.e., the dc-link is split in two. On the other hand, the dc-dc converter is a bidirectional buck-boost-type converter with frequency-doubler characteristic, i.e., the frequency of the ripple in the output current is the double of the switching frequency.

In section II is described in detail the principle of operation of the proposed converter, i.e., the combination of the ac-dc and the dc-dc converters for EV battery chargers. In section III is described the digital controller design, namely the power

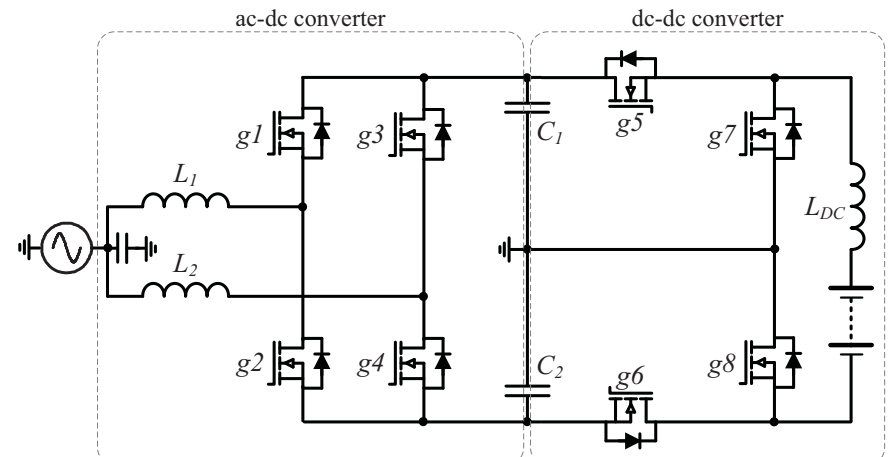

Fig. 1. Proposed bidirectional bridgeless interleaved converter for EV battery chargers. 


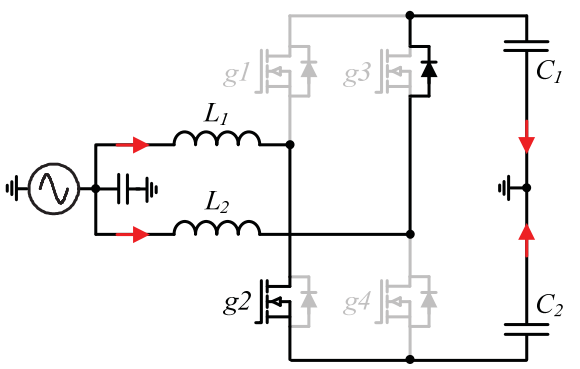

(a)

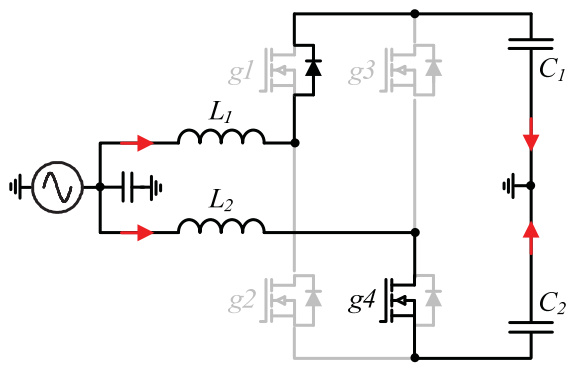

(b)

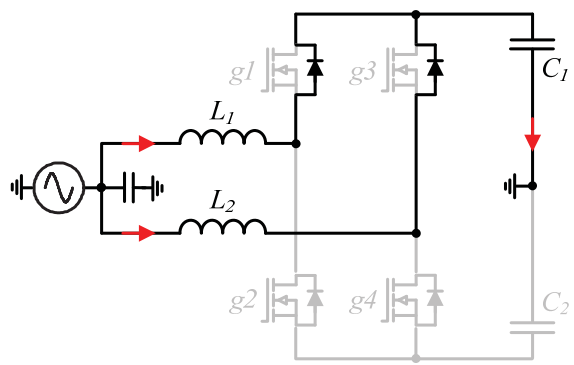

(c)

Fig. 2. Operation stages for the ac-dc converter: (a) $L_{1}$ stores energy and $L_{2}$ delivers energy; (b) $L_{1}$ delivers energy and $L_{2}$ stores energy; (c) $L_{1}$ and $L_{2}$ deliver energy.

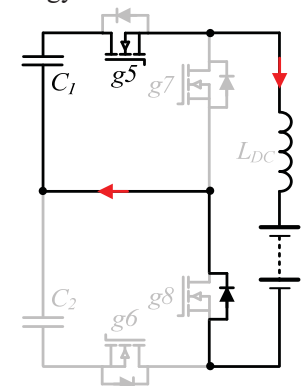

(a)

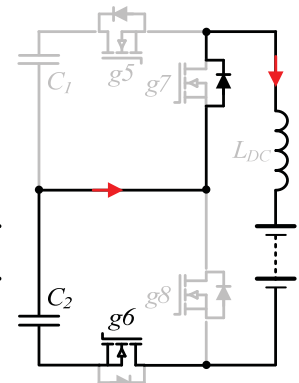

(b)

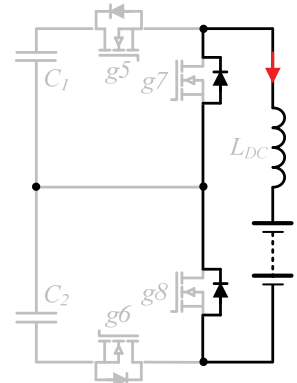

(c)

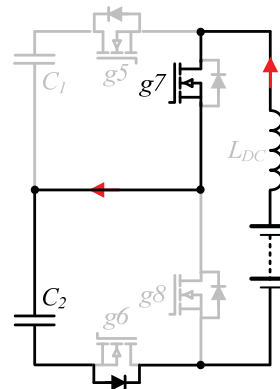

(d)

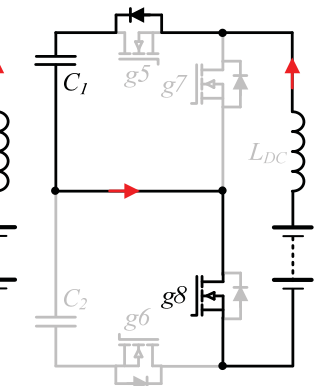

(e)

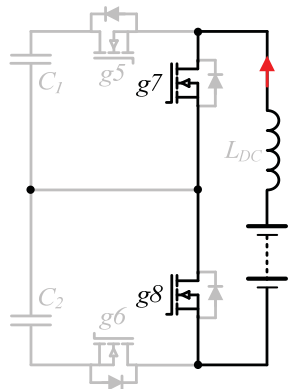

(f)

Fig. 3. Operation stages for the dc-dc converter: (a) $V_{D C 1}$ delivers energy and $L_{D C}$ stores energy during G2V; (b) $V_{D C 2}$ delivers energy and $L_{D C}$ stores energy during G2V; (c) $L_{D C}$ delivers energy during G2V; (d) $V_{D C 2}$ receives energy and $L_{D C}$ delivers energy during V2G; (e) $V_{D C 2}$ receives energy and $L_{D C}$ delivers energy during V2G; (f) $L_{D C}$ stores energy during V2G.

theory that allows obtain the grid current references and the current control strategy that allows synthetize the grid current references. In section IV are presented some simulation results of the proposed EV battery charger for a rated power of $3.5 \mathrm{~kW}$, both for G2V and V2G operation modes. Finally, section $\mathrm{V}$ presents the main conclusions.

\section{PRINCIPLE OF OPERATION}

In this item is described in detail the principle of operation of the proposed converter, where the ac-dc and the dc-dc converters are described separately, both for $\mathrm{G} 2 \mathrm{~V}$ and $\mathrm{V} 2 \mathrm{G}$ operation modes. The operation stages of the ac-dc converter during the positive semi cycle are shown in Fig. 2. The ac-dc front-end converter has six main operation stages (three for each semi cycle). For the positive semi cycle, firstly, $L_{l}$ stores energy from the power grid and $L_{2}$ delivers energy to the dc-link (cf. Fig. 2(a)); Secondly, $L_{1}$ delivers energy to the dc-link and $L_{2}$ stores energy from the power grid (cf. Fig. 2(b)); Thirdly, $L_{1}$ and $L_{2}$ deliver energy to the dc-link (cf. Fig. 2(c)). The dc-dc back-end converter has six main operation stages. The operation stages of the dc-dc converter are shown in Fig. 3. During G2V operation mode there are three stages: Firstly, $V_{D C l}$ delivers energy and $L_{D C}$ stores energy (cf. Fig. 3(a)); Secondly, $V_{D C 2}$ delivers energy and $L_{D C}$ stores energy (cf. Fig. 3(b)); Thirdly, $L_{D C}$ delivers energy (cf. Fig. 3(c)); During V2G operation mode there are also three stages: Firstly, $V_{D C 2}$ receives energy and $L_{D C}$ delivers energy (cf. Fig. 3(d)); Secondly, $V_{D C 2}$ receives energy and $L_{D C}$ delivers energy (cf. Fig. 3(e)); Thirdly, $L_{D C}$ stores energy (cf. Fig. 3(f)).

\section{A. Front-end ac-dc Converter}

As shown in Fig. 1, the ac-dc converter is mainly composed by two MOSFETs legs (i.e., four MOSFETs), by two inductive filters, and by a split dc-link. The power grid phase is connected to the MOSFETs legs through the inductive filters, i.e., the grid current is split in two. The power grid neutral is connected to the middle point of the dc-link. Therefore, the voltage in the dc-link is always greater than the double of the maximum instantaneous value of the power grid voltage.

\section{1) G2V Operation Mode}

During G2V operation mode, the ac-dc converter is used to transfer energy from the power grid to the dc-link. Taking into account that the power grid phase is connected to the two MOSFETs legs, the converter can operates in interleaved mode, i.e., the maximum current in each leg is half of the grid current, the resultant switching frequency of the grid current is the double of the MOSFETs switching frequency, and the ripple of the grid current is reduced when compared with the traditional topology. With this converter, during the positive semi cycle are used the MOSFETs $g 2$ and $g 4$ and the reverse blocking diodes of the MOSFETs $g 1$ and $g 3$. During the negative semi-cycle are used the MOSFETs $g l$ and $g 3$ and the reverse blocking diodes of the MOSFETs $g 2$ and $g 4$. Fig. 4 shows in detail the grid current $\left(i_{g}\right)$, the current in the inductors $L_{1}$ and $L_{2}$ and the gate pulses of the MOSFETs $g 2$ and $g 4$.

\section{2) V2G Operation Mode}

During V2G operation mode, the ac-dc converter is used to transfer energy from the dc-link to the power grid. During this operation mode is applied the same reasoning that was described for $\mathrm{G} 2 \mathrm{~V}$ operation mode, i.e., the ac-dc converter can operate in interleaved mode and the ripple of the grid current is reduced compared with the traditional topology. During the positive semi cycle are used the MOSFETs $g 1$ and $g 3$ and the reverse blocking diodes of the MOSFETs $g 2$ and $g 4$. During the negative semi cycle are used the MOSFETs $g 2$ and $g 4$ and 


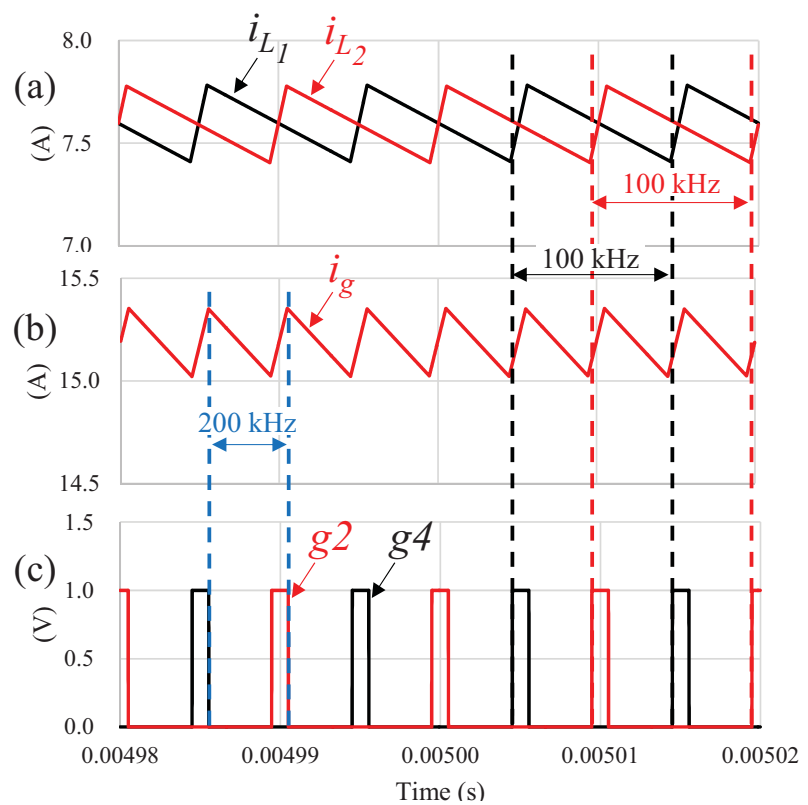

Fig. 4. G2V operation mode: (a) Grid current $\left(i_{g}\right)$; (b) Current in the inductances $L_{1}$ and $L_{2} ;$ (c) Gate pulses of the MOSFETs $g 2$ and $g 4$.

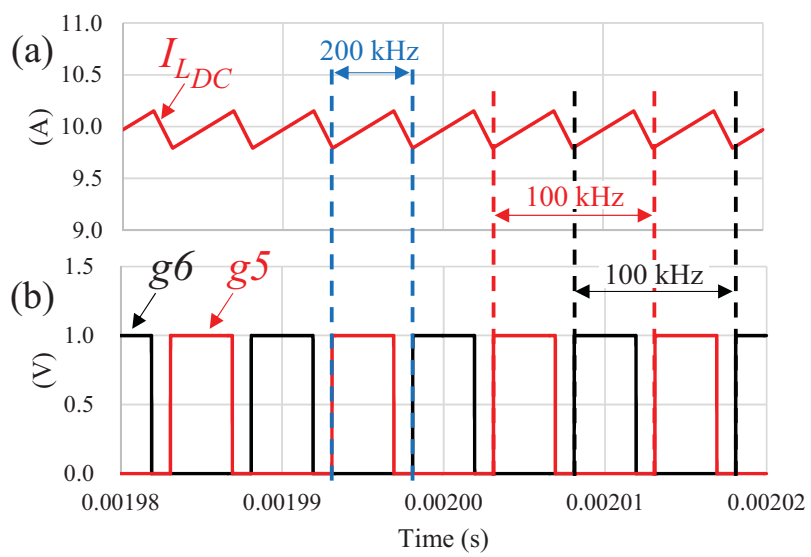

Fig. 5. G2V operation mode: (a) Output current $\left(I_{B A T}\right)$; (b) Gate pulses of the MOSFETs $g 5$ and $g 6$.

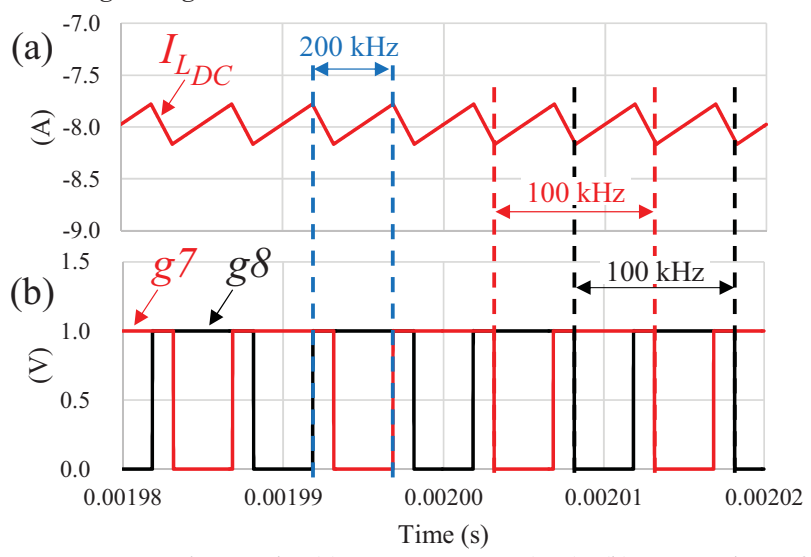

Fig. 6. V2G operation mode: (a) Output current $\left(I_{B A T}\right)$; (b) Gate pulses of the MOSFETs $g 7$ and $g 8$.

the reverse blocking diodes of the MOSFETs $g 1$ and $g 3$. In this operation mode is also applied the reasoning that was used to describe Fig. 4.

\section{B. Back-end dc-dc Converter}

As shown in Fig. 1, the dc-dc converter is mainly composed by four MOSFETs and by an inductive filter. The batteries are connected in series with the inductive filter allowing control the current or voltage in the batteries in both $\mathrm{G} 2 \mathrm{~V}$ and $\mathrm{V} 2 \mathrm{G}$ operation modes. The middle point of the dc-link is connected to the middle point of the leg formed by the MOSFETs $g 7$ and $g 8$ and the maximum output voltage is $V_{D C}$.

\section{1) G2V Operation Mode}

During G2V operation mode, the dc-dc converter is used to transfer energy from the dc-link to the batteries. Taking into account that the middle point of the dc-link is split and connected to the middle point of the leg formed by the MOSFETs $g 7$ and $g 8$, the dc-dc converter can operate in a virtual interleaved mode, i.e., the resultant switching frequency in the output current is the double of the MOSFETs switching frequency, and the ripple is also reduced when compared with the traditional buck-type topology. During G2V operation mode are used the MOSFETs $g 5$ and $g 6$ and the reverse blocking diodes of the MOSFETs $g 7$ and $g 8$. Fig. 5 shows in detail the output current $\left(I_{B A T}\right)$ and the gate pulses of the MOSFETs $g 5$ and $g 6$.

\section{2) V2G Operation Mode}

During the $\mathrm{V} 2 \mathrm{G}$ operation mode, the dc-dc converter is used to transfer energy from the batteries to the dc-link. In this operation mode is applied the same reasoning that was described for $\mathrm{G} 2 \mathrm{~V}$ operation mode, i.e., the dc-dc converter can operate in a virtual interleaved mode, where the resultant switching frequency in the output current is the double of the MOSFETs switching frequency, and the ripple is also reduced when compared with the traditional boost-type topology. During V2G operation mode are used the MOSFETs $g 7$ and $g 8$ and the reverse blocking diodes of the MOSFETs $g 5$ and $g 6$. Fig. 6 shows in detail the output current $\left(I_{B A T}\right)$ and the gate pulses of the MOSFETs $g 7$ and $g 8$.

\section{Digital Controller Design}

In this section are presented the main steps of the digital controller design, namely, the power theory and the current control strategy for the ac-dc and dc-dc converters.

\section{A. Power Theory}

The power theory that allows obtain the grid current references for the EV battery charger is described in this section. To simplify the power theory description, it is assumed that the power grid voltage is composed only by the fundamental component. It is important to refer that in the digital controller is used a phase-locked loop (PLL) algorithm, allowing to obtain sinusoidal references to the grid current. In order to track the positive sequence component of the fundamental voltage it was used a single-phase phase-locked loop presented in [24]. Assuming the single-phase power grid voltage $\left(v_{g}\right)$ and the single-phase grid current $\left(i_{g}\right)$ defined, respectively, by:

$$
v_{g}=\sqrt{2} V_{g} \operatorname{sen}(\omega t),
$$




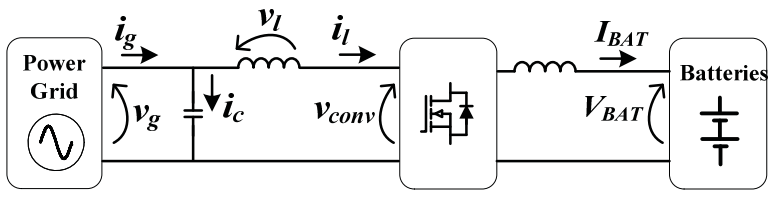

Fig. 7. Representation of the voltages and currents in the proposed converter.

$$
i_{g}=\sqrt{2} I_{g} \operatorname{sen}(\omega t+\varphi),
$$

the active power $\left(P_{g}\right)$ in the ac side is defined by:

$$
P_{g}=V_{g} I_{g} \cos (\varphi)
$$

Taking into account that the proposed converter operates with sinusoidal current and high power factor, the power grid voltage $\left(v_{g}\right)$ and the grid current $\left(i_{g}\right)$ are in phase, i.e., $\varphi=0$. Therefore, it can be defined a conductance $(G)$ according to:

$$
G=\frac{P_{g}}{V_{g}^{2}},
$$

where, $V_{g}$ corresponds to the rms value of the power grid voltage. Using the conductance defined in (4), the instantaneous grid current reference can be defined by:

$$
i_{g}{ }^{*}=G \text { pll } \sqrt{2} V_{g},
$$

where, pll has unitary amplitude. For the proposed converter, neglecting the losses, the active power $P_{g}$ can be separately in two terms corresponding, respectively, to the power to maintain constant the dc-link voltage $\left(V_{D C}\right)$ and the power to charge the batteries (through the dc-dc back-end converter). Therefore, substituting the conductance presented in (5) is obtained:

$$
i_{g}^{*}=\frac{P_{D C}+V_{B A T} I_{B A T}}{V_{g}^{2}} p l l \sqrt{2} V_{g},
$$

where, $P_{D C}$ is obtained using a PI controller.

\section{B. Current Control Strategy}

In order to simply the description of the current control strategy, Fig. 7 shows the equivalent circuit of the proposed converter for EV battery chargers.

\section{1) Front-end ac-dc Converter}

From Fig. 7, analyzing the voltages and currents between the power grid and the converter, it can be established for the current grid $\left(i_{g}\right)$ and for the voltage grid $\left(v_{g}\right)$ that:

$$
\begin{gathered}
i_{g}=i_{c}+i_{l}, \\
v_{g}=v_{l}+v_{\text {conv }} .
\end{gathered}
$$

Substituting the current in the capacitor $\left(i_{c}\right)$ by the time derivative of its voltage multiplied by its capacitance, it can be established:

$$
i_{g}=C \frac{d v_{g}}{d t}+i_{l} .
$$

Substituting (7) and (8) in (9) and rearranging in order to the voltage $\left(v_{\text {conv }}\right)$ that the converter must produce is obtained:

$$
v_{\text {conv }}=v_{g}-L \frac{d i_{g}}{d t}+L C \frac{d^{2} v_{g}}{d t^{2}} .
$$

Taking into account that is used a digital control strategy, the derivative of the power grid current $\left(i_{g}\right)$ in (10) can be substituted by its discrete implementation using the forward Euler method according to:

$$
\frac{d i_{g}}{d t}=\frac{i_{g}[k+1]-i_{g}[k]}{T_{s}},
$$

and the second order derivative of the power grid voltage in (10) can be substituted by its discrete implementation defined as:

$$
\frac{d^{2} v_{g}}{d t^{2}}=\frac{v_{g}[k+1]-2 v_{g}[k]+v_{g}[k-1]}{T_{s}^{2}} .
$$

Using (11) and (12), the discrete implementation of (10) results in:

$$
\begin{aligned}
& v_{\text {conv }}[k]=v_{g}[\mathrm{k}]-L f_{S}\left(i_{g}[k+1]-i_{g}[k]\right)+ \\
& +C L f_{S}^{2}\left(v_{g}[k+1]-2 v_{g}[k]+v_{g}[k-1]\right),
\end{aligned}
$$

where, $f_{s}$ is the sampling frequency, $k, k-1, k+1$, are respectively, the actual, previous and next samples, and the current in the instant $k+1\left(i_{g}[k+1]\right)$ should be equal to the current reference in the instant $k\left(i_{g} *[k]\right)$. Therefore, (13) can be rewritten for:

$$
\begin{aligned}
& v_{\text {conv }}[k]=v_{g}[\mathrm{k}]-L f_{s}\left(i_{g}{ }^{*}[k]-i_{g}[k]\right)+ \\
& +C L f_{S}^{2}\left(v_{g}[k+1]-2 v_{g}[k]+v_{g}[k-1]\right) .
\end{aligned}
$$

In order to compute (13) is necessary know the value of the power grid voltage $\left(v_{g}\right)$ in the instant $k+1$. This value can be obtained according to:

$$
v_{g}[k+1]=3 v_{g}[k]-3 v_{g}[k-1]+v_{g}[k-2] \text {. }
$$

Substituting (15) in (14) is obtained the final current control law that allows control the grid current of the proposed converter. The voltage $v_{\text {conv }}[k]$ is the reference that is compared with a $100 \mathrm{kHz}$ center-aligned triangular carrier in order to control the state of the MOSFETs. In order to the ac-dc converter operates as interleaved are used two triangular carriers lagged 180 degrees, i.e., to obtain the gate pulses to the MOSFETs $g 2$ and $g 4$ during the positive semi cycle (cf. Fig. 4) and to the MOSFETs $g 1$ and $g 3$ during the negative semi cycle. It is important to refer that this current control strategy is applied for both $\mathrm{G} 2 \mathrm{~V}$ and $\mathrm{V} 2 \mathrm{G}$ operation modes.

\section{2) Back-end dc-dc Converter}

During G2V operation mode, the dc-dc converter operates as buck-type converter. From Fig. 7, analyzing the voltages and currents between the converter and the batteries, it can be established:

$$
V_{D C-D C}=V_{B A T}+L_{D C} \frac{d I_{B A T}}{d t} .
$$

where, $V_{B A T}$ and $I_{B A T}$ are, respectively, the voltage and current in the batteries. The discrete implementation of (16) results in:

$$
\begin{gathered}
V_{D C-D C}[k]=V_{B A T}[k]+ \\
+L_{D C} f_{S}\left(I_{B A T}[k+1]-I_{B A T}[k]\right) .
\end{gathered}
$$

where, $I_{B A T}[k+1]$ must be equal to the reference in the instant $[k]$. During V2G operation mode, the dc-dc converter operates as boost-type converter. From Fig. 7, it can be established:

$$
V_{D C-D C}=V_{B A T}-L_{D C} \frac{d I_{B A T}}{d t} \text {. }
$$


where, $V_{D C}$ is the dc-link voltage. The discrete implementation of (18) results in:

$V_{D C-D C}[k]=V_{B A T}-L_{D C} f_{S}\left(I_{B A T}[k+1]-I_{B A T}[k]\right)$,

where, $I_{B A T}[k+1]$ must be equal to the reference in the instant $[k]$. Taking into account that the current will follow in opposite sense, in the digital implementation the current $\left(I_{B A T}[k]\right)$ represented in (19) should be $\left(-I_{B A T}[k]\right)$. In order to the dc-dc converter operates as a virtual interleaved are used two triangular carriers lagged 180 degrees, i.e., to obtain the gate pulses to the MOSFETs $g 5$ and $g 6$ during G2V operation mode (cf. Fig. 5) and to the MOSFETs $g 7$ and $g 8$ during $V 2 G$ operation mode (cf. Fig. 6).

\section{Simulation RESUlts}

This section presents the main simulation results of the proposed converter, which were achieved with PSIM 9.0 software. In the simulation results were considered Li-Ion batteries as example of batteries of EVs. Table I shows the specification and key components of the proposed converter for EV battery chargers. According to the aforementioned principle of operation (cf. Section II), Fig. 8 shows the power grid voltage $\left(v_{g}\right)$ and the grid current $\left(i_{g}\right)$ during G2V (cf. Fig. 8(a)) and V2G (cf. Fig. 8(b)) operation modes. As it can be seen, during G2V operation mode the power grid voltage and the grid current are in phase, meaning that the energy flows from the power grid to the batteries. This result was obtained with an input power of $3.5 \mathrm{~kW}$. On the other hand, during V2G operation mode the power grid voltage and the grid current are in phase opposition, meaning that the energy flows from the batteries to the power grid. This result was obtained with an output power of $2 \mathrm{~kW}$. Fig. 9 shows in detail the ripple of the dc-link voltage in each capacitor $\left(C_{l}\right.$ and $C_{2}$ ). Taking into account that the ac-dc converter is single-phase converter the dc-link voltage is not constant. Therefore, in order to avoid introduce the dc-link voltage oscillation into the control is used the mean value of the dc-link voltage, which is obtained according with:

$$
\overline{V_{D C}[k]}=\frac{1}{T} \sum_{n=1}^{T} V_{D C}[n] .
$$

Fig. 10 shows the battery charging current $\left(I_{B A T}\right)$ and voltage $\left(V_{B A T}\right)$ during a complete Li-Ion battery charging process. From this figure it can be observed that the battery charging process consists of two charging stages: constant current followed by constant voltage. In the first stage the batteries were charged with a constant current of $10 \mathrm{~A}$ during about 3.5 hours, i.e., until the voltage reaches the specified value. In the second stage the batteries were charged with a constant voltage of $300 \mathrm{~V}$ during about 2.5 hours, i.e., until the current consumed by the batteries falls to a residual value. It is important to refer that this charging algorithm can be adjusted for other nominal values as well as for other technologies of batteries. Using the thermal module of the software PSIM (considering the dynamic behavior of real semiconductors towards estimating switching and conduction losses), it was possible estimate the efficiency of the proposed EV battery charger for a power range from $500 \mathrm{~W}$ to $3.5 \mathrm{~kW}$. Fig. 11 shows the estimated efficiency. Besides the losses in the semiconductors (estimating conduction and switching losses),
TABLE I

SPECIFICATION AND KEY COMPONENTS OF THE PROPOSED CONVERTER

\begin{tabular}{ccc}
\hline \hline Parameters & Value & Unit \\
\hline Grid Voltage (line-to-neutral) & $230 \pm 10 \%$ & $\mathrm{~V}$ \\
Grid Frequency & $50 \pm 1 \%$ & $\mathrm{~Hz}$ \\
Maximum Input Power & 3.5 & $\mathrm{~kW}$ \\
Output dc Voltage Range & 100 to 400 & $\mathrm{~V}$ \\
Maximum Output Current & 10 & $\mathrm{~A}$ \\
Total Power Factor @ Full Load & 0.99 & - \\
Switching Frequency & 100 & $\mathrm{kHz}$ \\
\hline Capacitor $C$ & 2 & $\mu \mathrm{F}$ \\
Inductors $L_{1}, L_{2}$ & 2 & $\mathrm{mH}$ \\
Inductor $L_{D C}$ & 1 & $\mathrm{mH}$ \\
Dc-link Capacitors $C_{l}, C_{2}$ & 5 & $\mathrm{mF}$ \\
\hline \hline
\end{tabular}
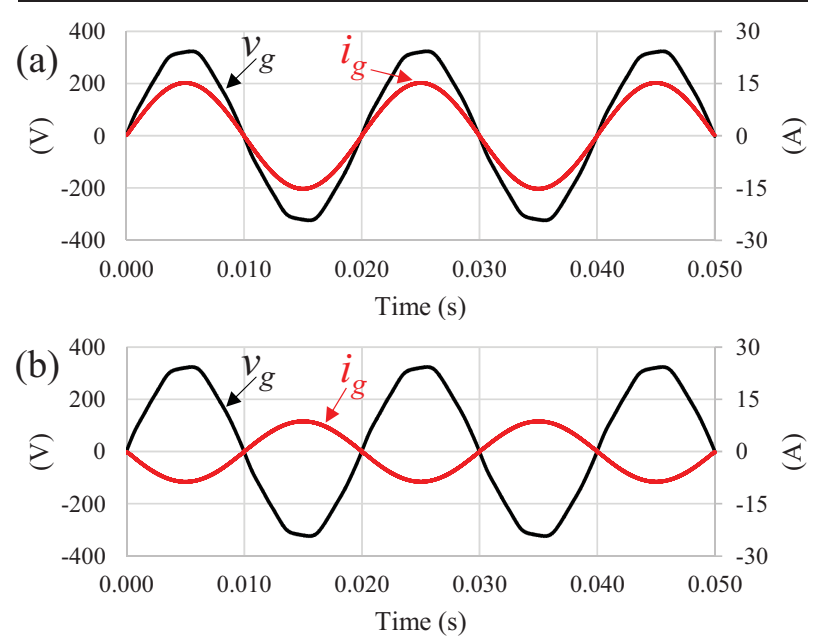

Fig. 8. Power grid voltage $\left(v_{g}\right)$ and grid current $\left(i_{g}\right)$ during: (a) G2V operation mode; (b) V2G operation mode.

were also considered the losses in the input and output passive filters.

\section{CONCLUSION}

This paper presents a novel architecture of a bidirectional bridgeless interleaved converter specially dedicated for electric vehicles (EVs) battery chargers. The proposed converter is composed by two power stages: an ac-dc converter and a dc-dc converter. The ac-dc converter is an interleaved bridgeless bidirectional boost-type converter, and the dc-dc converter is a bidirectional buck-boost-type converter. The presented simulation results shows that the proposed converter operates with sinusoidal grid current and with high power factor in both grid-to-vehicle (G2V) and vehicle-to-grid (V2G) operation modes. The proposed converter was simulated during a complete EV Li-Ion battery charging process, which consists in two charging stages: constant current followed by constant voltage. Along the paper is described in detail the proposed converter for EV battery chargers: the circuit topology, the principle of operation, the power control theory, and the current control strategy.

\section{ACKNOWLEDGMENT}

This work has been supported by FCT - Fundação para a Ciência e Tecnologia in the scope of the project: PEstUID/CEC/00319/2013. Mr. Vítor Monteiro was supported by the doctoral scholarship SFRH/BD/80155/2011 granted by the FCT agency. 


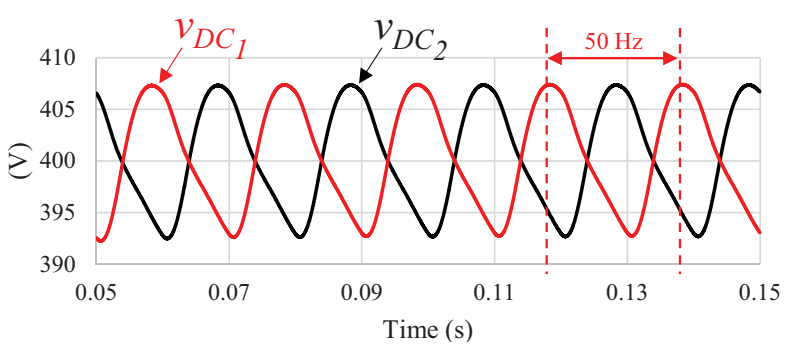

Fig. 9. Ripple of the dc-link voltage in each capacitor $\left(C_{I}\right.$ and $\left.C_{2}\right)$.

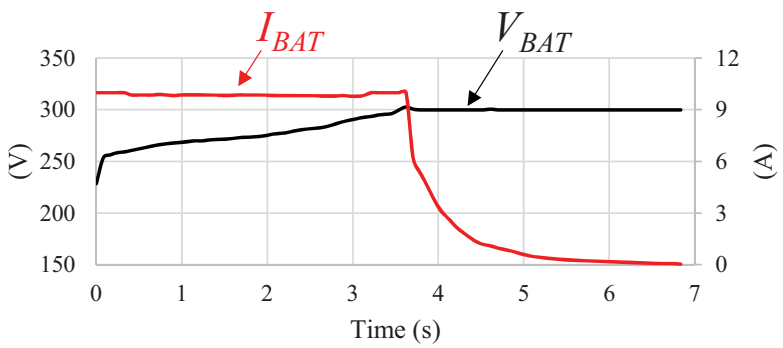

Fig. 10. Battery charging current $\left(I_{B A T}\right)$ and voltage $\left(V_{B A T}\right)$ during a complete Li-Ion battery charging process.

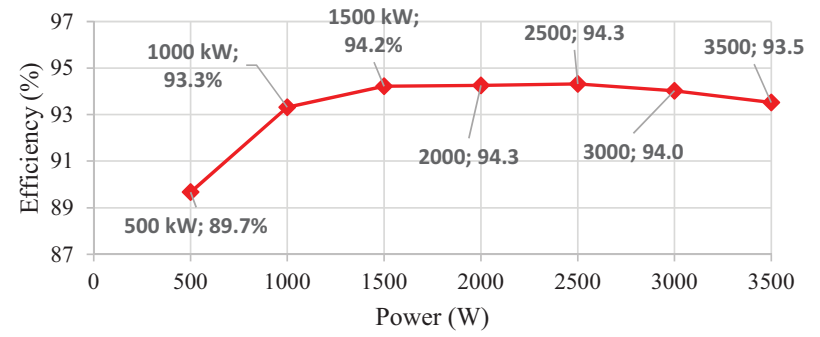

Fig. 11. Estimated efficiency of the proposed EV battery charger for a power range from $500 \mathrm{~W}$ to $3.5 \mathrm{~kW}$.

\section{REFERENCES}

[1] Kaushik Rajashekara, "Present Status and Future Trends in Electric Vehicle Propulsion Technologies," IEEE J. Emerg. Sel. Topics Power Electron., vol.1, no.1, pp.3-10, Mar. 2013.

[2] Seshadri Srinivasa Raghavan, Alireza Khaligh, "Electrification Potential Factor: Energy-Based Value Proposition Analysis of Plug-In Hybrid Electric Vehicles," IEEE Trans. Veh. Technol., vol.61, no.3, pp.1052-1059, Mar. 2012.

[3] Vítor Monteiro, Bruno Exposto, J. G. Pinto, Raul Almeida, João C. Ferreira, Andrés A. Nogueiras Meléndez, João L. Afonso, “On-Board Electric Vehicle Battery Charger with Enhanced V2H Operation Mode", IEEE IECON Industrial Electronics Conference, pp.1636-1642, Dallas Texas USA, Oct. 2014.

[4] Mithat C. Kisacikoglu, Burak Ozpineci, Leon M. Tolbert, "Examination of a PHEV Bidirectional Charger System for V2G Reactive Power Compensation," IEEE APEC Applied Power Electronics Conference and Exposition, pp.458-465, Feb. 2010.

[5] Vítor Monteiro, J. G. Pinto, Bruno Exposto, João C. Ferreira, Carlos Couto, João L. Afonso, "Assessment of a Battery Charger for Electric Vehicles with Reactive Power Control," IEEE IECON Industrial Electronics Society, Montréal-Canada, pp.5124-5129, Oct. 2012.

[6] Farzad Rajaei Salmasi, "Control Strategies for Hybrid Electric Vehicles: Evolution, Classification, Comparison, and Future Trends," IEEE Trans. Veh. Technol., vol.56, no.5, pp.2393-2404, Sept. 2007.

[7] João A. Peças Lopes, Filipe Soares, Pedro M. Rocha Almeida, "Integration of Electric Vehicles in the Electric Power Systems," Proc. IEEE, vol.99, no.1, pp.168-183, Jan. 2011.
[8] João Paulo M. Figueiredo, Fernando L. Tofoli, Bruno Leonardo A. Silva, "A Review of Single-Phase PFC Topologies Based on The Boost Converter," IEEE INDUSCON International Conference on Industry Applications, pp.1-6, Nov. 2010.

[9] Huai Wei, Issa Batarseh, "Comparison of Basic Converter Topologies for Power Factor Correction," IEEE Proceedings of Southeastcon, pp.348-353, Apr. 1998.

[10] T. Soeiro, M. Heldwein, J. W. Kolar, "Three-Phase Modular Multilevel Current Source Rectifiers for Electric Vehicles Battery Charging Systems," COBEP Brazilian Power Electronics Conference, pp.1-7, Gramado Brasil, Oct. 2013

[11] T. Soeiro, T. Friedli, J. W. Kolar, "Three-Phase High Power Factor Mains Interface Concepts for Electric Vehicle Battery Charging Systems," IEEE APEC Applied Power Electronics Conference and Exposition, pp.2603-2610, Feb. 2012.

[12] Murat Yilmaz, Philip T. Krein, "Review of Battery Charger Topologies, Charging Power Levels, and Infrastructure for Plug-In Electric and Hybrid Vehicles," IEEE Trans. Power Electron., vol.28, no.5, pp.2151-2169, May 2013.

[13] Johann W. Kolar, Thomas Friedli, "The Essence of Three-Phase PFC Rectifier Systems-Part I,” IEEE Trans. Power Electron., vol.28, no.1, pp.176-198, Jan. 2013.

[14] Thomas Friedli, Michael Hartmann, Johann W. Kolar, "The Essence of Three-Phase PFC Rectifier Systems-Part II," IEEE Trans. Power Electron., vol.29, no.2, pp.543-560, Feb. 2014.

[15] Oscar García, José A. Cobos, Roberto Prieto, Pedro Alou, Javier Uceda, "Single Phase Power Factor Correction: A Survey," IEEE Transactions on Power Electronics, vol.18, no.3, pp.749-755, May 2003.

[16] Yun-Sung Kim, Won-Yong Sung, Byoung-Kuk Lee, "Comparative Performance Analysis of High Density and Efficiency PFC Topologies,” IEEE Trans. Power Electron., vol.29, no.6, pp.2666-2679, June 2014.

[17] Woo-Young Choi, Jung-Min Kwon, Bong-Hwan Kwon, “An Improved Bridgeless PFC Boost-Doubler Rectifier With High-Efficiency,” IEEE PESC Power Electronics Specialists Conference, Rohdes, pp.13091313, June 2008

[18] J. Biela, J.W. Kolar, G. Deboy, "Optimal Design of a Compact 99.3\% Efficient Single-Phase PFC Rectifier," IEEE APEC Applied Power Electronics Conference and Exposition, Palm Springs, CA, pp.13971404, Feb. 2010.

[19] José Rodríguez, Jih-Sheng Lai, Fang Zheng Peng, "Multilevel Inverters: A Survey of Topologies, Controls, and Applications," IEEE Trans. Ind. Electron., vol.49, no.4, pp.724-738, Aug. 2002.

[20] Jih-Sheng Lai, Fang Zheng Peng, "Multilevel Converters-A New Breed of Power Converters," IEEE Trans. Ind. Appl., vol.32, no.3, pp.509517, May 1996.

[21] Mamadou Baïlo Camara, Hamid Gualous, Frederic Gustin, Alain Berthon, Brayima Dakyo, "DC/DC Converter Design for Supercapacitor and Battery Power Management in Hybrid Vehicle Applications-Polynomial Control Strategy," IEEE Trans. Ind. Electron., vol.57, no.2, pp.587-597, Feb. 2010.

[22] Oscar García, Pablo Zumel, Angel de Castro, José A. Cobos, "Automotive DC-DC Bidirectional Converter MadeWith Many Interleaved Buck Stages,” IEEE Trans. Power Electron., vol.21, no.3, pp.578-586, May 2006.

[23] Yu Du, Xiaohu Zhou, Sanzhong Bai, Srdjan Lukic, Alex Huang, "Review of Non-isolated Bi-directional DC-DC Converters for Plug-in Hybrid Electric Vehicle Charge Station Application at Municipal Parking Decks," IEEE APEC Applied Power Electronics Conference and Exposition, Palm Springs, CA, pp.1145-1151, Feb. 2010.

[24] Masoud Karimi-Ghartemani, "Linear and Pseudolinear Enhanced Phased-Locked Loop (EPLL) Structures,” IEEE Trans. Ind. Electron., vol.61, no.3, pp.1464-1474, Mar. 2014. 